Dominguez, R., Cannella, S., Póvoa, A.P., Framinan, J.M. 2018. OVAP: A strategy to implement partial information sharing among supply chain retailers. Transportation Research Part E: Logistics and Transportation Review, 110, 122-136. DOI: https://doi.org/10.1016/j.tre.2017.12.016

\title{
OVAP: A strategy to implement partial information sharing among supply chain retailers
}

\author{
Roberto Dominguez ${ }^{\mathrm{a}, *}$, Salvatore Cannella ${ }^{\mathrm{b}, \mathrm{c}}$, Ana P. Barbosa-Póvoa ${ }^{\mathrm{a}}$, Jose M. Framinan ${ }^{\mathrm{c}}$ \\ ${ }^{a}$ Centre for Management Studies, Instituto Superior Técnico (CEG-IST), Technical University of Lisbon, \\ Portugal \\ ${ }^{b}$ DICAR, University of Catania, Catania, Italy \\ ${ }^{\mathrm{c}}$ Industrial Management \& Business Administration Department, School of Engineering, University of \\ Seville, Spain \\ E-Mail: roberto.dominguez@tecnico.ulisboa.pt, cannella@us.es, apovoa@tecnico.ulisboa.pt, \\ framinan@us.es
}

*Corresponding author: Roberto Dominguez, Centre for Management Studies (CEG-IST), Instituto Superior Técnico, Technical University of Lisbon, Ave. Rovisco Pais 1, 1049-001, Lisbon, Portugal.

\begin{abstract}
This paper analyses the impact on supply chain performance of adopting different strategies to implement partial information sharing among heterogeneous retailers. Supply chains are modelled using a multi-agent systems approach. We find that the strategy adopted to construct the partial information sharing structure (i.e., the retailers who share information) has a significant impact on supply chain performance. We propose a practical strategy, named Order VAriance Prioritization (OVAP), which gives priority to the retailers with higher order variance. OVAP outperforms the worst (i.e. naive) implementation method by $27.2 \%$ and $7.8 \%$ with respect to the levels of bullwhip and average inventory.
\end{abstract}

Keywords: Supply chain management; partial information sharing; heterogeneous retailers; bullwhip effect; multi-agent model; OVAP. 
Dominguez, R., Cannella, S., Póvoa, A.P., Framinan, J.M. 2018. OVAP: A strategy to implement partial information sharing among supply chain retailers. Transportation Research Part E: Logistics and Transportation Review, 110, 122-136. DOI: https://doi.org/10.1016/j.tre.2017.12.016

\section{INTRODUCTION}

\subsection{Context and motivation}

Information Sharing (IS) has been acknowledged as an effective practice for coordination among the nodes of decentralized Supply Chains (SCs), improving the global performance and reducing production and logistics inefficiencies caused by the bullwhip effect (Ali et al. 2012, Chatfield et al. 2004, Dejonckheere et al. 2004, Lee et al. 1997, Shan et al. 2014, Trapero et al. 2012, Wang and Disney 2016). However, there are numerous barriers to the implementation of IS in SCs (Ali et al. 2017, Spekman and Davis 2016) including the risk of information leakage (Huang et al. 2016, Kong et al. 2013), lack of trust (Shnaiderman and Ouardighi 2014), resource investments in Information Technology (Gunasekaran et al. 2017, Kembro et al. 2014), wide variety of technology and tools (Ramanathan 2014), different types of information (Rached et al. 2016, Yu et al. 2010), information distortion (Jeong and Leon 2012, Niranjan et al. 2011), and unbalanced share of gains between SC members (Lee and Whang 2000, Rached et al. 2015, Shih et al. 2015). These barriers, together with the decentralization and globalization of modern SCs make it difficult to achieve a full/perfect IS among SC members and thus, this assumption deviates from real-life in some cases (Huang and Wang 2017). As a consequence, partial IS is a prevalent scenario in real-life SCs (Shnaiderman and Ouardighi 2014, Xu et al. 2015, Zhou et al. 2009).

According to the literature, partial IS in SCs takes place when the information is asymmetrically shared among SC members (see e.g. Gümüş 2014, Gunasekaran et al. 2015, Inderfurth et al. 2013, Li et al. 2016, Zhou et al. 2017a), delayed (see e.g. Hoberg and Thonemann 2014, Hosoda and Disney 2012), partially revealed (Zhang et al. 2016), shared only between some members of the SC (see e.g. Ganesh et al. 2014a,b, Lau et al. 2004, Huang and Wang 2017), or inaccurate, either intentionally (see e.g. Huang et al. 2017, Shnaiderman and Ouardighi 2014) or unintentionally (see e.g. Cannella et al. 2015, Kwak and Gavirneni 2015). A specific case of partial IS occurs when the information is symmetrically, timely and accurately shared, but takes place only between some members of the SC. In fact, it is common that some members of SC do not participate in IS, particularly at the retailer stage (empirical evidence showed that only $27 \%$ of retailers shared POS data with other members, see Shang et al. 2016). Nevertheless, despite being a common practice, there is a lack of academic studies on the topic (Holmström et al. 
Dominguez, R., Cannella, S., Póvoa, A.P., Framinan, J.M. 2018. OVAP: A strategy to implement partial information sharing among supply chain retailers. Transportation Research Part E: Logistics and Transportation Review, 110, 122-136. DOI: https://doi.org/10.1016/j.tre.2017.12.016

2016). To the best of authors' knowledge, there are only five studies addressing this theme: Costantino et al. (2014) and Ganesh et al. (2014a,b) analyse how different degrees of collaboration between SC members impact the bullwhip effect, inventory holding and shortage costs, and/or customer service levels in a serial SC. Lau et al. (2004) analyse partial IS in three divergent SCs with increasing complexity. Finally, Huang and Iravani (2005) analyse a SC with one capacitated manufacturer and two different retailers where the former may receive demand and inventory information from any of the retailers.

All these works agree that retailers provide, by sharing customer demand information, the highest performance improvement for SCs with respect to other members (e.g. wholesalers and distributors). Nevertheless, an important limitation of the above studies is that they assume - with the exception of Lau et al. (2004) - a single retailer in the SC. However, real SCs often include more than one retailer (Wan and Evers 2011) and, due to the complexities of modern SCs, retailers may operate under different market scenarios (e.g. different customer demand) and/or Operational Factors (OFs) (e.g. lead time, inventory order policies, forecasting methods, etc.). These implications concern both traditional SCs (i.e., SCs without IS) and partial IS SCs that are willing to adopt or upgrade the IS strategy (i.e., to incorporate new retailers). In cases where it is undesirable or infeasible to transform the current (traditional or partial IS) SC into a full IS SC, where all retailers share information with upstream echelons, it is of great interest to define a strategy to incorporate new retailers in IS by identifying the retailer(s) who can provide the highest global performance improvement by sharing market demand information with upstream members. In this manner, a roadmap for implementing IS can be devised in order to capture most IS benefits at a reduced cost. Despite its potential, to the best of the authors' knowledge, the analysis of different strategies for implementing partial information sharing among heterogeneous retailers has not been previously addressed.

Thus, it is important to understand how to select the most suitable retailers taking into account that 1) they are usually heterogeneous and 2) upstream members often lack visibility regarding retailers' internal processes and policies. A practical and user-friendly method for identifying appropriate retailers is to analyse retailers' order patterns and, more specifically, the variability of orders. There are two main reasons to follow such an approach: (1) orders are one of the few data transmitted upstream by retailers in a traditional SC, and (2), IS is known to be more beneficial in a SC where members have to face higher order variability (Chatfield and Pritchard 2013). According to these 
Dominguez, R., Cannella, S., Póvoa, A.P., Framinan, J.M. 2018. OVAP: A strategy to implement partial information sharing among supply chain retailers. Transportation Research Part E: Logistics and Transportation Review, 110, 122-136. DOI: https://doi.org/10.1016/j.tre.2017.12.016

considerations, we argue that IS might be more beneficial when it involves retailers who transmit upstream most of the variability of the orders in the SC, and by doing so, reduces their contribution to the demand amplification.

\subsection{Objectives and contribution}

Motivated by the considerations in the previous section, our research objectives are:

1. To determine the impact of the IS implementation strategy (i.e., how to select the appropriate retailers for IS) on SC performance when retailers are heterogeneous. More specifically, we intend to prove that the specific strategy adopted for IS implementation has a significant effect for the SC in terms of the bullwhip effect and inventory levels.

2. To propose and test (through simulation) a practical IS implementation strategy to achieve effective IS for SCs with heterogeneous retailers and partial IS, quantifying its benefits in terms of bullwhip and average inventory reductions. More specifically, we will show that our proposed strategy exploits most of IS capability under partial IS.

Such strategy, named Order VAriance Prioritization (OVAP), considers retailers' order variability to identify potential retailers for IS. As such, this is a "pre-assessment" strategy, since it is based on current information of the SC, and it can be determined prior to the performance assessment, avoiding the need of running a SC model. Consequently, OVAP can be implemented in practice. More specifically, OVAP determines the retailers for IS as follows:

Estimate retailers' order variance prior to IS implementation.

Generate a sequence of retailers, which are ranked from the highest to the lowest order variance (i.e., retailers with higher order variance are potentially better partners for IS).

In order to get more accurate dynamic insights, a model of an entire SC should be considered (Chatfield 2013). As such, to fulfil the research objectives we model a SC with four echelons (i.e., Factory, Distributor, Wholesaler and Retailer), each of them characterized by one member with the exception of the Retailer's echelon. In order to consider several partial IS structures and allow for a precise representation of the 
Dominguez, R., Cannella, S., Póvoa, A.P., Framinan, J.M. 2018. OVAP: A strategy to implement partial information sharing among supply chain retailers. Transportation Research Part E: Logistics and Transportation Review, 110, 122-136. DOI: https://doi.org/10.1016/j.tre.2017.12.016

performance of OVAP, we consider four retailers (see Figure 1). Each retailer may or may not share private market demand information with the Wholesaler (i.e., partial IS), who may use this data in his/her inventory control policy. Additionally, retailers are heterogeneous, as they face different market and geographical conditions. Such heterogeneity is specifically simulated by systematically varying three different OFs (i.e., average lead time, market demand variability, and forecasting period). Finally, since SC processes are often subject to uncertainty, we consider stochastic demand and lead times in order to obtain more realistic results.

To fulfil the first research objective, we define and compare two benchmarking strategies (i.e., BEST and WORST). These are "post-assessment" strategies, since they can be determined only after the assessment of the performance of all the possible partial IS structures, thus needing to run a SC model. More specifically, BEST selects the retailers who provide the best SC performance improvement, and WORST selects the retailers who provide the worst SC performance improvement. Consequently, BEST and WORST cannot be implemented in practice.

To fulfil the second research objective, OVAP is compared with BEST and WORST under several scenarios with partial IS and different levels of retailer heterogeneity. Since BEST and WORST represent the best and the worst possible IS implementation strategies, OVAP will have an intermediate performance. However, if OVAP performs close to BEST, then it can be concluded that OVAP is a good strategy to implement IS. As mentioned before, SC performance is assessed by measuring the bullwhip effect and the average inventory, so we adopt two system-level metrics, namely Bullwhip Slope and Systemic Inventory Level, which allow us to easily compare the global performance of different SCs (Cannella et al. 2013).

The inherent complexity of the SCs to be analysed, characterised by a divergent configuration, heterogeneous members facing stochastic demands and lead times, and where the collaboration to share market information takes place only among a few members, makes simulation a suitable approach to develop the models and perform the analysis. In fact, simulation, and particularly Multi-Agent Systems (MAS), has been recognised as an effective research methodology for complex systems modelling (see e.g., Costantino et al. 2016, Costantino et al. 2015a, Langroodi and Amiri 2016, Long 2015, or Ponte et al. 2016, 2017). More specifically, to develop the SC models we use SCOPE 
Dominguez, R., Cannella, S., Póvoa, A.P., Framinan, J.M. 2018. OVAP: A strategy to implement partial information sharing among supply chain retailers. Transportation Research Part E: Logistics and Transportation Review, 110, 122-136. DOI: https://doi.org/10.1016/j.tre.2017.12.016

(Dominguez and Framinan 2013), a MAS-based software tool for complex SC modelling. In order to perform a systematic analysis of the simulations, we adopt reasonable assumptions and data inputs for simulations obtained from different cases to emulate realworld logistic systems (Dominguez et al. 2017). SCOPE has been validated by contrasting the results obtained from the simulations with those reported by other authors. More specifically, in Dominguez and Framinan (2013), a four-stage serial SC has been modelled and the results (amplification of the standard deviation of orders) obtained by SCOPE are found to be in line with those provided by Chatfield et al. (2004), Chen et al. (2000), Dejonckheere et al. (2003).

The computational experience carried in Section 4 shows that there are significant differences in the performance of BEST and WORST, particularly for high levels of retailer heterogeneity, which indicates that the specific IS implementation strategy adopted is relevant for SC performance. Results also show that OVAP is a suitable IS implementation strategy that ensures a high SC performance improvement for any type of partial IS structure. More specifically, for certain levels of retailer heterogeneity, the SC performance improvement obtained by OVAP and BEST are identical in $93.33 \%$ and $84.44 \%$ of the scenarios analysed in terms of Bullwhip Slope and Systemic Inventory Level, respectively.

The remainder of this paper is as follows: Section 2 describes the SC model. Section 3 presents the design of experiments. In Section 4 we analyse the results obtained and provide the main findings of the work. Finally, Section 5 presents some industrial recommendations, concluding remarks, and future research lines.

\section{SUPPLY CHAIN MODEL}

The SC model is an extension of that by Chatfield et al. (2004) in order to model divergent SCs (see e.g. Dominguez et al. 2014), and it has been specifically developed to model partial IS.

Regarding the notation adopted in the model, subscript $i=1 \ldots E$ indicates the echelon's position in the SC, being $i=1$ the most upstream echelon. Subscript $j=1 \ldots N_{i}$ indicates node's position in echelon $i$, being $N_{i}$ the total number of nodes in echelon $i$. In addition, $N_{i} \geq N_{i-1}$ in order to model a divergent SC. A generic node in the SC can be denoted as 
Dominguez, R., Cannella, S., Póvoa, A.P., Framinan, J.M. 2018. OVAP: A strategy to implement partial information sharing among supply chain retailers. Transportation Research Part E: Logistics and Transportation Review, 110, 122-136. DOI: https://doi.org/10.1016/j.tre.2017.12.016

$n_{i j}$. In order to model the partial IS, we use a binary variable $\left(\delta_{i j}\right): \delta_{i j}=1$ if node $n_{i j}$ shares information with an upstream partner, and $\delta_{i j}=0$ otherwise.

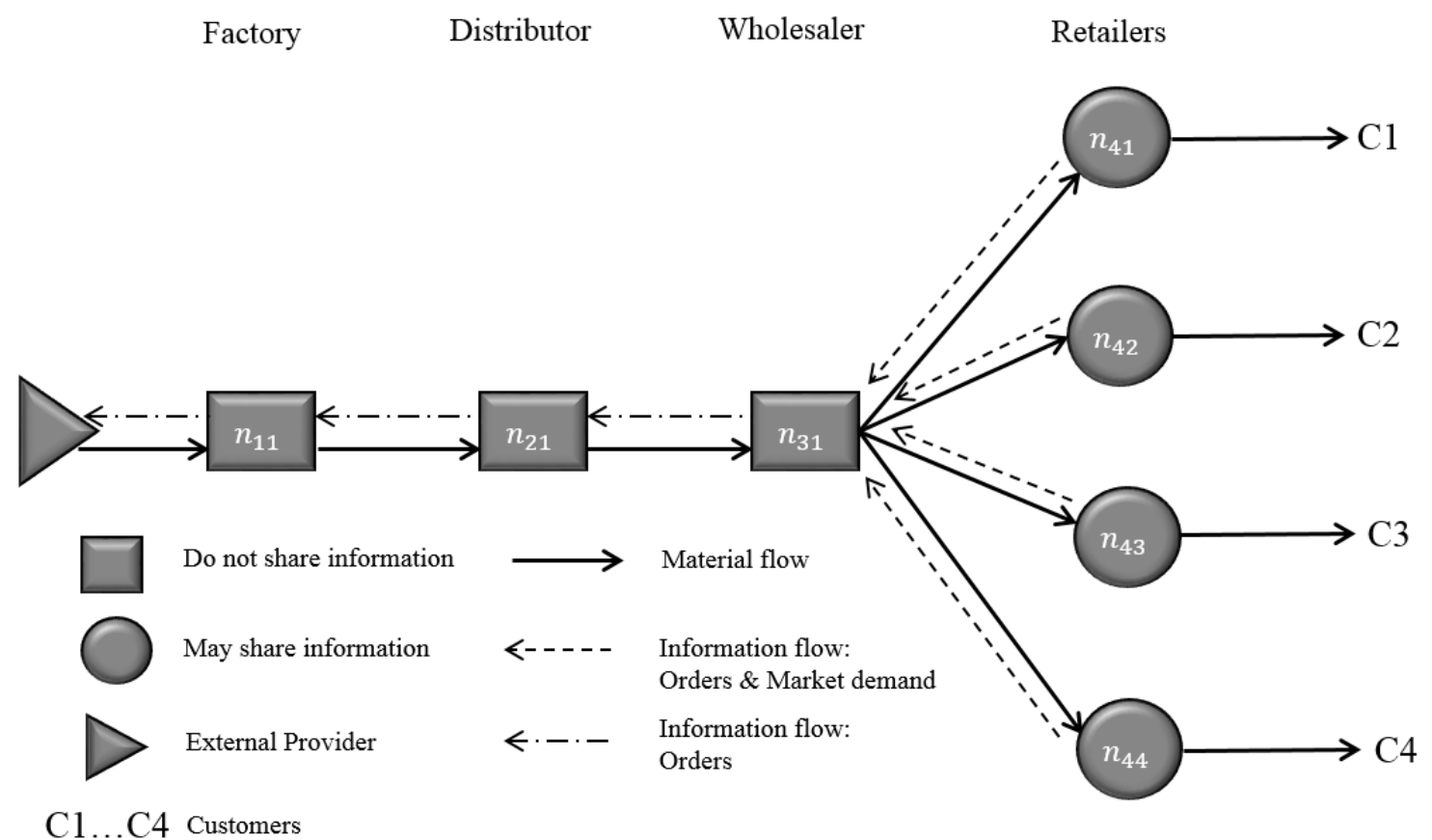

Figure 1. SC with partial IS at retailers.

In the following we describe the main modelling assumptions:

- Supply chain configuration: We adopt the commonly used four-echelon $(E=4)$ SC structure (see e.g. Chatfield et al. 2004, Sterman 1989). The reason is that, by considering an entire SC, we are able to get more accurate dynamic insights (Zhou et al. 2017b) and avoid underestimating the bullwhip effect (Chatfield 2013). In order to model partial IS at retailers, this SC model is extended by considering several retailers, resulting in a divergent SC. More specifically, we consider four retailers $\left(N_{i}=4 \forall i=4 ; N_{i}=1 \quad \forall i<4\right)$, since these numbers allow us to provide a detailed representation of the SC performance by considering several partial IS structures (see Figure 1). Retailers are the only SC members allowed to share demand information upstream $\left(\delta_{i j}=0,1 \forall i=4 ; \delta_{i j}=0 \forall i<4\right)$. In addition, we assume that this information can be received only by the immediate upstream partner, i.e. the Wholesaler (Kembro and Selviaridis 2015, Lau et al. 2004). 
Dominguez, R., Cannella, S., Póvoa, A.P., Framinan, J.M. 2018. OVAP: A strategy to implement partial information sharing among supply chain retailers. Transportation Research Part E: Logistics and Transportation Review, 110, 122-136. DOI: https://doi.org/10.1016/j.tre.2017.12.016

- $\quad$ Customer demands are stochastic, independent and identically distributed, and follow a normal distribution $\left(D_{C_{j}}^{t}\right)$ (Chatfield et al. 2004, Rekik et al. 2017).

- $\quad$ Capacity constraint. There is unlimited production, transportation and stocking capacity.

- Backlog. In the event of a stock-out situation, a node partially replenishes its customer with the remaining stock and backorder the excess of demand (Chatfield and Pritchard 2013).

- $\quad$ Return of excess inventory to upstream partners is not permitted, as it has been shown that this condition may alter the assessment of SC performance (Chatfield and Pritchard 2013, Dominguez et al. 2015b).

- $\quad$ Lead times of a node $n_{i j}\left(L_{i j}^{t}\right)$ are defined as the time elapsed between order and receipt, and are assumed to be stochastic, independent, and identically distributed. Lead times follow a Gamma distribution (see e.g., Bischak et al. 2014, Chatfield et al. 2004, Dominguez et al. 2015b, Hayya et al. 2011, among others). Since the simulation model is based on discrete time periods, we assume lead times to be integers. Therefore, values obtained from the Gamma distribution are discretized. Consequently, each time an order is generated, it is assigned a random integer lead time, which corresponds to the number of periods required for the order to arrive. Although the effect of stochastic lead times is not analysed when exposing the simulation results, we assume stochastic lead times as it better emulates real SCs. In fact, in many realistic situations, lead times depend on several uncertain events across the entire SC, and a number of researchers have shown lead-time variability to be an issue that significantly impacts on inventory models and systems (Bischak et al. 2014, Chaharsooghi, and Heydari 2010, Chatfield et al. 2004, Chatfield and Pritchard 2013, Kim et al. 2006, Hayya et al. 2011, Lin 2016, among others).

- $\quad$ Order crossovers are allowed, i.e., replenishment may be received in a different sequence than they were ordered (Bischak et al. 2014, Chatfield and Pritchard 2017, Disney et al. 2016, Hayya et al. 2008).

- $\quad$ Orders received. On period $t$, node $n_{i j}$ issues an order $O_{i j}^{t}$, and receives orders from a set $V_{i j}$ of downstream linked nodes. Total demand received by node $n_{i j}$ $\left(D_{i j}^{t}\right)$ can be then expressed as in Equation (1). 
Dominguez, R., Cannella, S., Póvoa, A.P., Framinan, J.M. 2018. OVAP: A strategy to implement partial information sharing among supply chain retailers. Transportation Research Part E: Logistics and Transportation Review, 110, 122-136. DOI: https://doi.org/10.1016/j.tre.2017.12.016

- $\quad$ Ordering policy. SC members use an adaptive $(R, S)$ periodic review policy (Babai et al. 2016, Li and Disney 2017, Li et al. 2014, Syntetos et al. 2016a, Zhou et al. $2017 \mathrm{~b}$ ), where $R$ is the review period. $S$ is the desired OUT level, and it is updated in every period. These type of policies are widely used in SCs (Bischak et al. 2014, Costantino et al. 2015b). Orders are placed at discrete time intervals according to the review period (we assume $R=1$, Chatfield et al. 2004) as in Equation (2), where $I P_{i j}^{t}$ is the inventory position, $W I P_{i j}^{t}$ is the work in progress, $I_{i j}^{t}$ is the current on hand inventory and $B_{i j}^{t}$ is backlog. The OUT level $\left(S_{i j}^{t}\right)$ is computed by a common approach as in Equation (3) (see e.g. Chatfield et al. 2004), where $z$ is a safety factor, $\bar{D}_{i j}^{t}$ and $s_{D_{i j}^{t}}^{2}$ are the estimations of demand average and variance, $\bar{L}_{i j}^{t}$ and $s_{L_{i j}^{t}}^{2}$ are the estimations of lead times average and variance (we assume the same $z$ for all nodes of the SC (Kim et al. 2006)).

- Demand forecast. A node $n_{i j}$ dynamically updates the forecast of incoming demand by a $\tau_{i j}$-periods moving averages/variances forecasting technique (Chatfield et al. 2004, Chen et al. 2000, Syntetos 2016b), as in Equations (4) and (5). Lead times are estimated by running averages and variances approaches, i.e. using all prior information available $\left(\tau_{i j}=t\right)$ (Cannella et al. 2017, Chatfield 2013).

$$
\begin{gathered}
D_{i j}^{t}=\sum_{r \in V_{i j}} O_{i+1, r}^{t} ; D_{E j}^{t}=D_{C_{j}}^{t} \\
O_{i j}^{t}=S_{i j}^{t}-I P_{i j}^{t}=S_{i j}^{t}-I_{i j}^{t}+B_{i j}^{t}-W I P_{i j}^{t} ; O_{i j}^{t} \geq 0 \\
S_{i j}^{t}=\left(\bar{L}_{i j}^{t}+1\right) \bar{D}_{i j}^{t}+z \sqrt{\left(\bar{L}_{i j}^{t}+1\right) s_{D_{i j}^{t}}^{2}+\bar{D}_{i j}^{t}{ }^{2} S_{L_{i j}^{t}}^{2}} \\
\bar{D}_{i j}^{t}=\frac{\sum_{k=1}^{\tau_{i j}} D_{i j}^{t-k}}{\tau_{i j}} \\
s_{D_{i j}^{t}}^{2}=\frac{1}{\tau_{i j}-1} \sum_{k=1}^{\tau_{i j}}\left(D_{i j}^{t-k}-\bar{D}_{i j}^{t-k}\right)^{2}
\end{gathered}
$$

- Partial information sharing. If a downstream node shares information with its upstream node, the latter can see the demand information from the downstream node, otherwise it only sees the order posed by the downstream node. As a consequence, since there might be several downstream linked nodes, the demand 
Dominguez, R., Cannella, S., Póvoa, A.P., Framinan, J.M. 2018. OVAP: A strategy to implement partial information sharing among supply chain retailers. Transportation Research Part E: Logistics and Transportation Review, 110, 122-136. DOI: https://doi.org/10.1016/j.tre.2017.12.016

information received by the upstream node or "shared demand" is a combination of downstream demand and downstream orders depending on whether the downstream nodes share demand information, or not. This is modelled as in Equation (6) where $S h D_{i j}^{t}$ is the shared demand. The upstream node then uses this information to forecast demand and determine the OUT level, which is modelled by replacing $D_{i j}^{t}$ by $S h D_{i j}^{t}$ in Equations (3), (4) and (5).

$$
S h D_{i j}^{t}=\sum_{r \in V_{i j}} \operatorname{Sh} D_{i+1, r}^{t} \delta_{i+1, r}+O_{i+1, r}^{t}\left(1-\delta_{i+1, r}\right)
$$

- Sequence of actions. For each period, each node $n_{i j}$ performs the following sequence of actions : (1) computes the $S_{i j}^{t}$ level using the forecast computed in the previous period; (2) if $S_{i j}^{t}>I P_{i j}^{t}$, places an order $O_{i j}^{t}$ and increases $W I P_{i j}^{t}$ accordingly; (3) receives the products from the upstream partner, reducing $W I P_{i j}^{t}$ and increasing $I_{i j}^{t}$ accordingly; (4) if $I_{i j}^{t}>0$, satisfies backorders, reducing $I_{i j}^{t}$ and $B_{i j}^{t}$ accordingly; (5) receives new orders from downstream linked nodes $\left(D_{i j}^{t}\right)$ and the demand information, in case that the node shares it $\left(\operatorname{Sh} D_{i j}^{t}\right)$. If $D_{i j}^{t} \leq I_{i j}^{t}$ satisfies demand and reduces $I_{i j}^{t}$ accordingly. If $D_{i j}^{t}>I_{i j}^{t}$ partially satisfies demand with the available inventory, reducing $I_{i j}^{t}$ accordingly $\left(I_{i j}^{t}=0\right)$, and backordering the unsatisfied demand $\left(B_{i j}^{t}=D_{i j}^{t}-I_{i j}^{t}\right)$; (6) forecast demand using updated shared demand information $\left(S h D_{i j}^{t}\right)$ and lead time for the next period $\left[\overline{S h D}_{i j}^{t}, s_{S h D_{i j}^{t}}^{2}, \bar{L}_{i j}^{t}, S_{L_{i j}^{t}}^{2}\right]$.

The SC model described in this section has been developed using SCOPE, a MAS-based SC simulator. This tool was implemented using the Swarm libraries, specifically designed to build MAS-based models (Minar et al. 1996). The scalability of MAS models allows SCOPE to create a wide range of SC configurations with any number of companies distributed along the SC. Agents can be updated with new behaviours, and can be individually customized. These features make SCOPE a suitable simulation platform to develop divergent SC models with partial IS and heterogeneous SC members. SCOPE was used to model and analyse complex SC problems in divergent SCs in some recent studies (see e.g., Cannella et al. 2017 and Dominguez et al. 2017). 
Dominguez, R., Cannella, S., Póvoa, A.P., Framinan, J.M. 2018. OVAP: A strategy to implement partial information sharing among supply chain retailers. Transportation Research Part E: Logistics and Transportation Review, 110, 122-136. DOI: https://doi.org/10.1016/j.tre.2017.12.016

\section{DESIGN OF EXPERIMENTS (DoE)}

The aim of the DoE is to generate a test-bed of different SCs with heterogeneous retailers in order to test the efficiency of the proposed implementation strategy (OVAP). In addition, OVAP will be benchmarked against the two post-assessment strategies BEST and WORST. Recall that these strategies, using the data obtained from the simulations, select the best and the worst retailers for IS, respectively.

The definition of the design of experiments entails the following aspects:

I. Emulation of heterogeneous retailers, definition of the levels of retailer heterogeneity and a variety of SCs.

II. Determination of model parameters.

III. Determination of SC performance metrics.

IV. Determination of the information sharing structures.

V. Definition of the benchmarking strategies: BEST and WORST.

These aspects are discussed in the following subsections.

\subsection{Emulation of heterogeneous retailers, definition of the levels of retailer heterogeneity and a variety of SCs}

To emulate heterogeneous retailers, we perform experiments by systematically varying three of their OFs, i.e., demand variance $\left(\sigma_{D_{C_{j}}}^{2}\right)$, forecasting period $\left(\tau_{i j}\right)$ and lead time average $\left(\mu_{L_{i j}}\right)$ (Dominguez et al. 2017). Considering that upstream members of the SC often lack visibility on retailers' internal processes and policies, we assume that retailers' OFs are unknown and thus, they are not within the scope of this study. To emulate this condition, we allow retailers' OFs to adopt random values. These values fall within an upper and a lower bound representing extreme values of the factors ( $U B$ and $L B$, respectively), with a uniform probability (Table 1). Bounds are chosen according to values typically adopted in other studies on SC dynamics. In particular, the $U B$ values employed can be found in Chatfield et al. (2013), Costantino et al. (2014) and Dominguez et al. (2017). $L B$ is obtained by reducing the $U B$ for each $O F$. 
Dominguez, R., Cannella, S., Póvoa, A.P., Framinan, J.M. 2018. OVAP: A strategy to implement partial information sharing among supply chain retailers. Transportation Research Part E: Logistics and Transportation Review, 110, 122-136. DOI: https://doi.org/10.1016/j.tre.2017.12.016

Table 1. Retailers' Operational factors.

\begin{tabular}{lcc}
\hline Retailers' Operational Factors (OFs) & $L B$ & $U B$ \\
\hline Demand variance $\left(\sigma_{D_{C_{j}}}^{2}\right)$ & $10^{2}$ & $20^{2}$ \\
Forecasting period $\left(\tau_{i j}\right)$ & 5 & 15 \\
Lead time average $\left(\mu_{L_{i j}}\right)$ & 2 & 4 \\
\hline
\end{tabular}

In order to test the performance of the OVAP strategy under different scenarios, we distinguish between different levels of retailer heterogeneity (i.e., how different are retailers among themselves). Note that retailers are heterogeneous because they have different OFs. Since retailers' OFs are assumed to be unknown to the upstream members of the SC, we adopt the retailers' order pattern as an indicator of the levels of retailer heterogeneity. In fact, retailers' OFs have a direct impact on retailers' order policy and thus, on how retailers place orders in each period (i.e., retailers' order variability). Thus retailers' order variability can be seen as a consequence of retailers' internal policies and operational environment. In this sense, we assume that retailers with similar order policies will react similarly to the environment (e.g., to market demand changes, lead times, etc.) and thus, if they also operate in a similar environment, they will place orders similarly. On the contrary, we assume that, if these retailers operate in different markets and/or with different lead times and/or they have different order policies, they will place orders adopting different rules. As such, we adopt the retailers' order pattern as an approximation to the levels of retailer heterogeneity.

On the basis of the above observations, we define the levels of retailer heterogeneity $(\psi)$ as the coefficient of variation of retailers' order variance c.v. $\left(s_{O_{E j}^{T}}^{2}\right)$ (Equation (7)) in the scenario of No IS (NIS), i.e., traditional SC. A high value of $\psi$ means that retailers are ordering with significantly different variance and thus, we consider that they are (strongly) heterogeneous. A low value of $\psi$ means that retailers are ordering with similar variance, and thus we assume that retailers are (weakly) heterogeneous. Finally, if $\psi=0$, retailers place orders with identical variance and they can be considered homogeneous for the upstream SC. 
Dominguez, R., Cannella, S., Póvoa, A.P., Framinan, J.M. 2018. OVAP: A strategy to implement partial information sharing among supply chain retailers. Transportation Research Part E: Logistics and Transportation Review, 110, 122-136. DOI: https://doi.org/10.1016/j.tre.2017.12.016

$$
\psi=\operatorname{c.v} \cdot\left(s_{O_{E j}^{T}}^{2}\right)=\frac{\operatorname{StdDev}\left(s_{O_{E j}^{T}}^{2}\right)}{\operatorname{Average}\left(s_{O_{E j}^{T}}^{2}\right)}=\frac{\sqrt{\frac{\sum_{j=1}^{N_{E}}\left(s_{O_{E j}^{T}}^{2}-\overline{s_{O_{E j}^{T}}^{2}}\right)^{2}}{N_{E}}}}{\overline{s_{O_{E j}^{T}}^{2}}} \forall j=1, \ldots, N_{E}
$$

$\psi$ is based on retailers' order patterns $\left(s_{O_{E j}^{T}}^{2}\right)$, and thus it is a consequence of retailers' internal policies and operational environment (i.e., the OFs). Hence, this indicator can be used to characterize the levels of retailer heterogeneity in SCs where retailers' OFs are not known in advance. However, $\psi$ does not give detailed information on how retailers' order variances are distributed. In fact, similar values of $\psi$ can be obtained using different combinations of retailers' order variances. As a consequence, we do not perform the analysis based on individual SCs; instead, we distinguish between classes of SCs with significantly different values of $\psi$ (i.e., low and high values) and test the implementation strategies - at an aggregate level - in such classes. To do so, we perform the following steps:

1. Generate a sample of 150 random SCs. SCs are instances of the model presented in Section 2, with the retailers' OFs randomly generated according to values shown in Table 1. As a result, each SC is randomly generated.

2. Simulate all the 150 SCs under the NIS scenario and compute $\psi$ for each of them, obtaining the following minimum and maximum values: $\psi_{\min }=0.028$ and $\psi_{\max }=0.802$.

3. In order to differentiate between SCs with two different levels of $\psi$, we:

a. Divide the interval between $\psi_{\min }$ and $\psi_{\max }$ in three identical parts (i.e., SCs with low, medium and high levels of $\psi$ ), namely $\psi_{L}, \psi_{M}$, and $\psi_{H}$, as shown in Table 2.

b. Build a test-bed of SCs by considering $15 \mathrm{SCs}$ in each of the two extreme classes of SCs, i.e., $\psi_{L}$ and $\psi_{H}$. Table 3 reports $\psi$ values for all of the SCs under analysis.

Table 2. Range of $\psi$ values obtained for the sample of 150 SCs.

\begin{tabular}{cccc}
\cline { 2 - 4 } & $\boldsymbol{\psi}_{\boldsymbol{L}}$ & $\boldsymbol{\psi}_{\boldsymbol{M}}$ & $\boldsymbol{\psi}_{\boldsymbol{H}}$ \\
\hline Lower bound & 0.028 & 0.286 & 0.544 \\
Upper bound & 0.286 & 0.544 & 0.802 \\
\hline
\end{tabular}


Dominguez, R., Cannella, S., Póvoa, A.P., Framinan, J.M. 2018. OVAP: A strategy to implement partial information sharing among supply chain retailers. Transportation Research Part E: Logistics and Transportation Review, 110, 122-136. DOI: https://doi.org/10.1016/j.tre.2017.12.016

Table 3. $\psi$ values for the test-bed of SCs.

\begin{tabular}{llllllllllllllll}
\hline \multirow{2}{*}{$\psi_{L}$} & SC1 & SC2 & SC3 & SC4 & SC5 & SC6 & SC7 & SC8 & SC9 & SC10 & SC11 & SC12 & SC13 & SC14 & SC15 \\
& 0.171 & 0.118 & 0.224 & 0.028 & 0.239 & 0.272 & 0.270 & 0.196 & 0.155 & 0.268 & 0.208 & 0.171 & 0.124 & 0.156 & 0.044 \\
\hline \multirow{2}{*}{$\psi_{H}$} & SC16 & SC17 & SC18 & SC19 & SC20 & SC21 & SC22 & SC23 & SC24 & SC25 & SC26 & SC27 & SC28 & SC29 & SC30 \\
& 0.546 & 0.780 & 0.550 & 0.619 & 0.589 & 0.544 & 0.547 & 0.752 & 0.802 & 0.569 & 0.568 & 0.569 & 0.575 & 0.671 & 0.660 \\
\hline
\end{tabular}

\subsection{Determination of model parameters}

Model parameters, which are common for all SC nodes -summarised in Table 4- are chosen as usual values used in SC dynamics literature (see, e.g., Chatfield 2013, Costantino et al. 2014, Dominguez et al. 2015a). Demand average and variance are not applicable to the upstream members of the SC (indicated as N.A. in Table 4). Some of the parameters of retailers coincide with the retailer's OFs (indicated as OF in Table 4).

Table 4. Summary of model parameters.

\begin{tabular}{lcc}
\hline Model parameters & Retailers & Upstream Members \\
\hline Demand average $\left(\mu_{D_{C_{j}}}\right)$ & 50 & N.A. \\
Demand variance $\left(\sigma_{D_{C_{j}}}^{2}\right)$ & OF & N.A. \\
Lead time average $\left(\mu_{L_{i j}}\right)$ & OF & 4 \\
Lead time c.v. & 0.50 & 0.50 \\
Forecasting period $\left(\tau_{i j}\right)$ & OF & 15 \\
Safety factor $(z)$ & 2(service $97.72 \%)$ & 2 (service $97.72 \%)$ \\
\hline
\end{tabular}

\subsection{Determination of SC performance metrics}

Due to the high number of different SCs to be analysed (see Section 3.4), we adopt system level performance metrics. By doing so, we are able to compute the global performance of the SC instead of computing echelons' performance individually, thus allowing an easy comparison between different SCs (Cannella et al. 2017). The adopted performance metrics are the Bullwhip Slope $(\mathrm{BwSl})$, to measure the global bullwhip effect of the SC, and the Inventory Average $(\operatorname{InvAv})$, to measure the total average inventory of the SC (Cannella et al. 2013).

$B w S l$ is computed as in Equation (8), where $\mathrm{ORVrR}_{i}$ is the Order Variance Ratio in echelon $i$ (Chen et al. 2000), which is calculated as $O R V r R_{i}=\left(\sum_{j=1}^{N_{i}} s_{O_{i j}^{T}}^{2}\right) /\left(\sum_{j=1}^{N_{C}} s_{D_{C_{j}}^{T}}^{2}\right)$ 
Dominguez, R., Cannella, S., Póvoa, A.P., Framinan, J.M. 2018. OVAP: A strategy to implement partial information sharing among supply chain retailers. Transportation Research Part E: Logistics and Transportation Review, 110, 122-136. DOI: https://doi.org/10.1016/j.tre.2017.12.016

for divergent SCs (Dominguez et al. 2015b), $N_{C}$ is the number of customers in the SC, $\pi_{i}$ is the position of the $i$-th echelon in Dejonckheere's et al. curve, and $T$ is the total simulation time. InvAv is computed as the average inventory held by all members of the SC over the observation period (Cannella et al. 2013), as per Equation (9).

$$
\begin{gathered}
B w S l=\frac{E \sum_{i=1}^{E} \pi_{i} O R V r R_{i}-\sum_{i=1}^{E} \pi_{i} \sum_{i=1}^{E} O R V r R_{i}}{E \sum_{i=1}^{E} \pi_{i}^{2}-\left(\sum_{i=1}^{E} \pi_{i}\right)^{2}} \\
\operatorname{InvAv}=\frac{\sum_{i=1}^{E} \sum_{j=1}^{N_{i}} \sum_{t=1}^{T} I_{i j}^{t}}{T}
\end{gathered}
$$

In order to benchmark two different IS implementation strategies (e.g., Strategy_1 and Strategy_2), we use the percentage increase of SC performance obtained by the Strategy_2 over the Strategy_1 $\left(\Delta\right.$ metric $\left._{\text {Strategy_1 } \rightarrow \text { Strategy_2 }}(\%)\right)$, where metric can be either $B w S l$ or InvAv (Equation (10)).

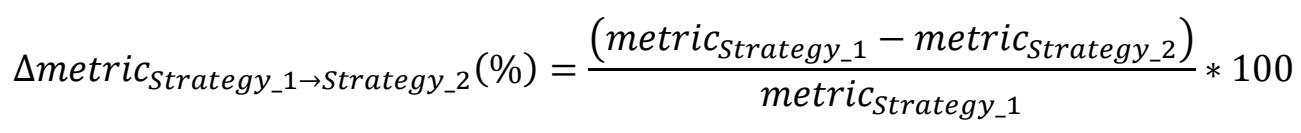

\subsection{Determination of the information sharing structures}

Let $\sum_{j=1}^{N_{E}} \delta_{E j}$ be the degree of retailer collaboration (i.e., the number of retailers sharing information). For the SCs under analysis, the possible IS structures range from NIS with $\sum_{j=1}^{4} \delta_{4 j}=0$ to Full IS (FIS) with $\sum_{j=1}^{4} \delta_{4 j}=4$. Between NIS and FIS are the partial IS structures, with $\sum_{j=1}^{4} \delta_{4 j} \in[1,3]$, namely $1 R I S, 2 R I S$, and $3 R I S$. Since retailers are heterogeneous, under partial IS we need to distinguish all the possible combinations of retailers for each IS structure, e.g., a $2 R I S$ structure defined by $\delta_{E j}=[1,1,0,0]$ (named $\left.2 R I S_{12}\right)$ is different than a $2 R I S$ structure defined by $\delta_{E j}=[0,1,1,0]$ (named $2 R I S_{23}$ ). A summary of all IS structures is provided in Table 5.

\subsection{Definition of the benchmarking strategies: BEST and WORST}

Two theoretical strategies, namely BEST and WORST, are used for benchmarking. These are "post-assessment" IS strategies, since they are determined after the assessment of the performance of all the partial IS structures. In particular, for a given performance metric (i.e., $B w S l$ or InvAv), BEST (WORST) is obtained by selecting the retailers who provide the best (worst) SC performance improvement for each partial IS structure, as follows: 
Dominguez, R., Cannella, S., Póvoa, A.P., Framinan, J.M. 2018. OVAP: A strategy to implement partial information sharing among supply chain retailers. Transportation Research Part E: Logistics and Transportation Review, 110, 122-136. DOI: https://doi.org/10.1016/j.tre.2017.12.016

1. For IRIS, select the best (worst) of four retailers, i.e., select the specific IS structure $\left(1 R I S_{x}\right)$ that obtains the lowest (highest) value of metric (best (worst) performance). We denote such IS structure by $1 R I S_{x}$.

2. For $2 R I S$, select the best (worst) of the three remaining retailers, i.e., select the specific IS structure $\left(2 R I S_{x^{\prime} y}\right.$, with $\left.y \neq x^{\prime}\right)$ that obtains the lowest (highest) value of metric. We denote such IS structure by $2 R I S_{x^{\prime}} y^{\prime}$.

3. For $3 R I S$, select the best (worst) of the two remaining retailers, i.e., select the specific IS structure $\left(3 R I S_{x^{\prime} y^{\prime} z} ; z \neq x^{\prime}, y^{\prime}\right)$ that obtains the lowest (highest) value of metric. We denote such IS structure by $3 R I S_{x^{\prime} y^{\prime} z^{\prime}}$.

4. The BEST (WORST) IS implementation strategy, which select the best (worst)

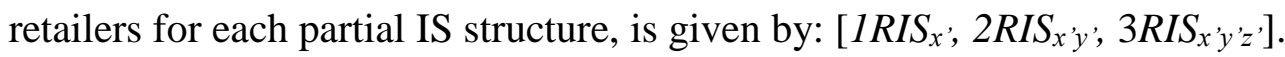

Table 5. Summary of IS structures.

\begin{tabular}{lcll}
\hline Type of IS & Degree of retailer collaboration & IS structure & Specific IS structure \\
\hline No IS & $\sum_{j=1}^{4} \delta_{4 j}=0$ & NIS & N.A. \\
& $\sum_{j=1}^{4} \delta_{4 j}=1$ & $1 R I S$ & $1 R I S_{1}, 1 R I S_{2}, 1 R I S_{3}, 1 R I S_{4}$ \\
Partial IS & $\sum_{j=1}^{4} \delta_{4 j}=2$ & $2 R I S$ & $2 R I S_{12}, 2 R I S_{13}, 2 R I S_{14}, 2 R I S_{22}$, \\
& $\sum_{j=1}^{4} \delta_{4 j}=3$ & & $2 R I S_{23}, 2 R I S_{24}, 2 R I S_{34}$ \\
& $\sum_{j=1}^{4} \delta_{4 j}=4$ & $3 R I S$ & $3 R I S_{123}, 3 R I S_{124}, 3 R I S_{134}, 3 R I S_{234}$ \\
Full IS & & & \\
& & & \\
\hline
\end{tabular}

A summary of the DoE is presented in Table 6. We run a total of 16 IS structures (Table 5) on 30 SCs (Table 3), totalling 480 experiments. In order to account for randomness, we run 30 replications of each experiment (Cannella et al. 2017, Chatfield et al. 2004) and the simulation outputs are statistically analysed. To ensure a steady state of the system we set the simulation time to 4,000 periods, and to eliminate system's initialization effects we remove the first 1,000 periods as a warm-up time. 
Dominguez, R., Cannella, S., Póvoa, A.P., Framinan, J.M. 2018. OVAP: A strategy to implement partial information sharing among supply chain retailers. Transportation Research Part E: Logistics and Transportation Review, 110, 122-136. DOI: https://doi.org/10.1016/j.tre.2017.12.016

Table 6. Summary of DoE.

\begin{tabular}{|c|c|c|c|c|}
\hline \multirow{3}{*}{ SCs } & \multicolumn{2}{|c|}{ OVAP } & \multicolumn{2}{|c|}{ BEST \& WORST } \\
\hline & IS structures & Required & IS structures & Required \\
\hline & & Information & & Information \\
\hline$\psi_{L}: \mathrm{SC} 1->\mathrm{SC} 15$ & & & & \\
\hline$\psi_{H}: \mathrm{SC} 16->\mathrm{SC} 30$ & $\sum_{j=1} \delta_{4 j}=$ & $S_{O_{O}}$ & $\sum_{=1} \delta_{4}$ & $B w S l \& \operatorname{Inv} A v$ \\
\hline
\end{tabular}

\section{ANALYSIS AND RESULTS}

The results are presented in two sections in line with the research objectives presented in Section 1.2:

1. BEST vs WORST: First we analyse the performance obtained when the best and the worst decisions regarding the retailers are selected for the different partial IS structures (IRIS, 2RIS, 3RIS). As discussed before, our first research objective is to study whether the specific strategy for IS adopted is relevant in terms of SC performance.

2. OVAP: This analysis aims at comparing the results obtained by OVAP with those obtained by BEST and WORST. Obviously, OVAP cannot outperform the postassessment BEST but, if the differences are small, then it could be concluded that OVAP is able to capture most of the benefits of the BEST while being a preassessment strategy.

\subsection{Determining the relevance of the adopted IS implementation strategy on a SC with heterogeneous retailers: BEST vs WORST}

Figure 2 shows average values obtained for $B w S l$ and $I n v A v$ adopting the BEST and WORST strategies from NIS to FIS. Along with the averages, 95\% confidence intervals (CIs) are also plotted. Since we cannot present graphics for all the analysed SCs, we present some exemplary results obtained for 4 out of 30 SCs (2 SCs belonging to $\psi_{L}$ and the other 2 SCs belonging to $\psi_{H}$ ). Curves show a decreasing function on the degree of retailer collaboration: as the degree of retailer collaboration increases, the SC performance improves. This result does not depend on the strategy adopted, as the improvement is observed for both BEST and WORST. However, the shape of the curves 
Dominguez, R., Cannella, S., Póvoa, A.P., Framinan, J.M. 2018. OVAP: A strategy to implement partial information sharing among supply chain

retailers. Transportation Research Part E: Logistics and Transportation Review, 110, 122-136. DOI: https://doi.org/10.1016/j.tre.2017.12.016

obtained are different, being convex for BEST and concave for WORST. Since both curves share common start and end points, these results suggest that a better SC performance is obtained if a partial IS structure is configured according to the BEST strategy.

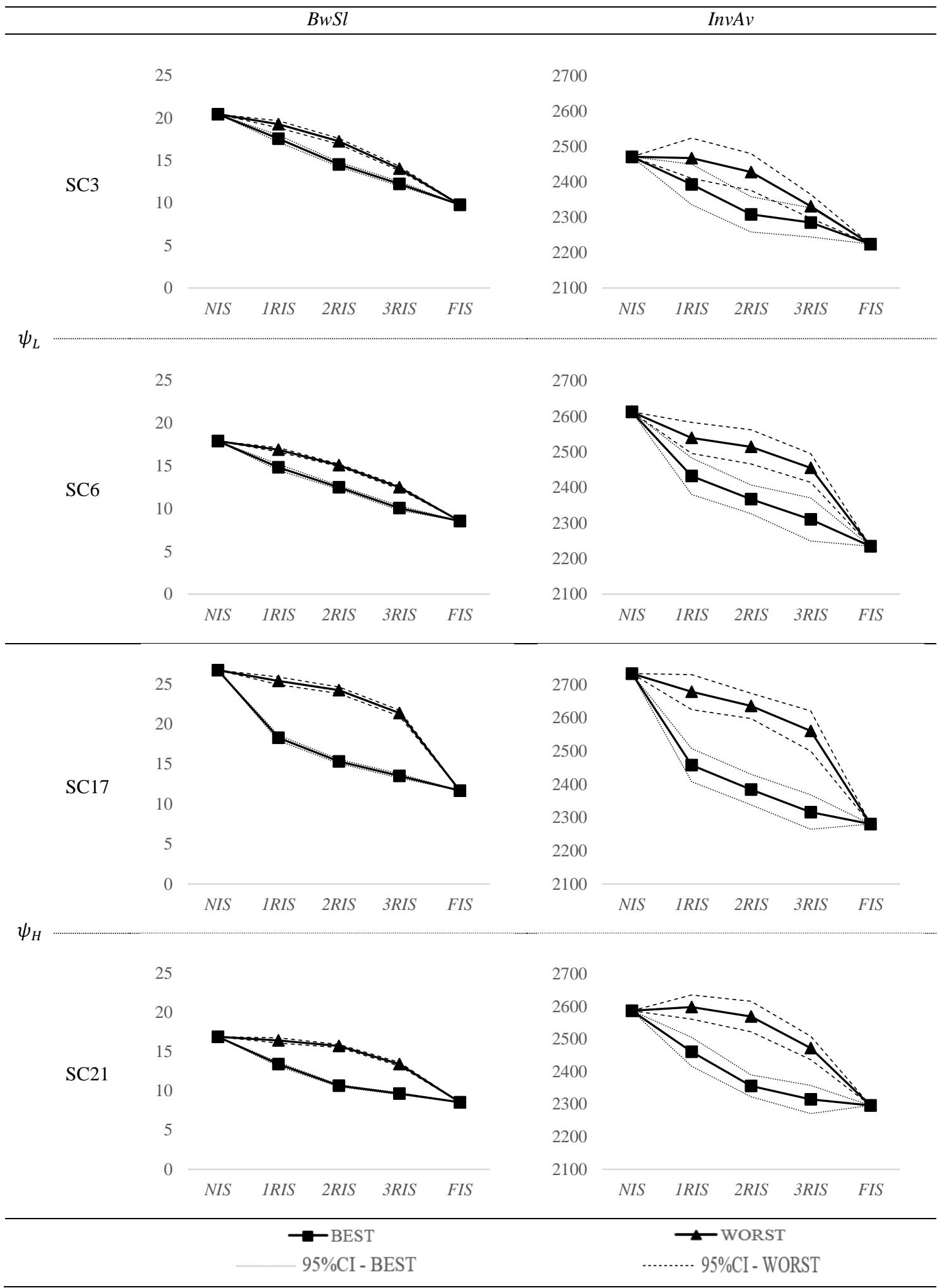

Figure 2. $B w S l$ and $I n v A v$ for BEST and WORST strategies. 
Dominguez, R., Cannella, S., Póvoa, A.P., Framinan, J.M. 2018. OVAP: A strategy to implement partial information sharing among supply chain retailers. Transportation Research Part E: Logistics and Transportation Review, 110, 122-136. DOI: https://doi.org/10.1016/j.tre.2017.12.016

To confirm the above results we look at the CIs. Results obtained for $B w S l$ show very tight CIs (i.e., CIs are very close to the averages), thus suggesting that there are significant $B w S l$ differences between BEST and WORST for each partial IS structure and for both $\psi_{L}$ and $\psi_{H}$. Nevertheless, these differences are more important for SCs in $\psi_{H}$ (i.e., SC17 and SC21). Results obtained for InvAv show wider CIs. For this metric, results suggest that there are significant differences between BEST and WORST only for the SCs in $\psi_{H}$. For the SCs in $\psi_{L}$, these differences are lower, obtaining some overlapping of CIs for SC3.

In order to contrast these preliminary results, we take into consideration the full test-bed of SCs. As a first step, we calculate $95 \%$ CIs to verify the robustness of the results obtained for $B w S l$ and InvAv and check for significant difference between BEST and WORST for each partial IS structure. Table 7 shows a summary of results for all the scenarios (i.e., 30 SCs x 3 partial IS structures $=90$ scenarios) and both metrics.

Table 7. Summary of the significance of the results obtained for BEST and WORST (95\% CI).

\begin{tabular}{|c|c|c|c|c|c|c|c|c|c|}
\hline \multirow{2}{*}{\multicolumn{2}{|c|}{$\begin{array}{r}*: \text { significant } \\
X: \text { not significant }\end{array}$}} & \multicolumn{3}{|c|}{$B w S l$} & \multirow[t]{2}{*}{$\%$ stat. Sig. } & \multicolumn{3}{|c|}{$\operatorname{Inv} A v$} & \multirow[t]{2}{*}{ \% stat. Sig. } \\
\hline & & IRIS & $2 R I S$ & $3 R I S$ & & IRIS & $2 R I S$ & $3 R I S$ & \\
\hline \multirow{15}{*}{$\psi_{L}$} & SC1 & $*$ & $*$ & $*$ & \multirow{15}{*}{$86.67 \%$} & $*$ & $X$ & $X$ & \multirow{15}{*}{$42.22 \%$} \\
\hline & $\mathrm{SC} 2$ & $*$ & $*$ & $*$ & & $\mathrm{X}$ & $\mathrm{X}$ & $\mathrm{X}$ & \\
\hline & SC3 & $*$ & $*$ & $*$ & & $\mathrm{X}$ & $*$ & $\mathrm{X}$ & \\
\hline & $\mathrm{SC} 4$ & $\mathrm{X}$ & $\mathrm{X}$ & $\mathrm{X}$ & & $\mathrm{X}$ & $\mathrm{X}$ & $\mathrm{X}$ & \\
\hline & SC5 & $*$ & $*$ & $*$ & & $*$ & $X$ & $*$ & \\
\hline & SC6 & $*$ & $*$ & $*$ & & $*$ & $*$ & $*$ & \\
\hline & SC7 & $*$ & $*$ & $*$ & & $*$ & $X$ & $*$ & \\
\hline & SC8 & $*$ & $*$ & $*$ & & $*$ & $*$ & $\mathrm{X}$ & \\
\hline & SC9 & $*$ & $*$ & $*$ & & $X$ & $*$ & $\mathrm{X}$ & \\
\hline & SC10 & $*$ & $*$ & $*$ & & $X$ & $*$ & $*$ & \\
\hline & SC11 & $X$ & $X$ & $*$ & & $X$ & $X$ & $X$ & \\
\hline & SC12 & $*$ & $*$ & $*$ & & $\mathrm{X}$ & $\mathrm{X}$ & $*$ & \\
\hline & SC13 & $*$ & $*$ & $*$ & & $*$ & $\mathrm{X}$ & $\mathrm{X}$ & \\
\hline & SC14 & $*$ & $*$ & $*$ & & $*$ & $*$ & $*$ & \\
\hline & SC15 & $\mathrm{X}$ & $*$ & $*$ & & $\mathrm{X}$ & $\mathrm{X}$ & $\mathrm{X}$ & \\
\hline$\psi_{H}$ & SC16-SC30 & $*$ & $*$ & $*$ & $100 \%$ & $*$ & $*$ & $*$ & $100 \%$ \\
\hline
\end{tabular}

Results suggest that there are significant differences between BEST and WORST for all the scenarios in $\psi_{H}$ for both metrics. However, as the heterogeneity of retailers decreases $\left(\psi_{L}\right)$, there are some scenarios where these differences are not significant. In fact, it seems 
logical that the variation of retailers' order variance in these scenarios is low and, as a consequence, the choice between BEST or WORST strategies does not make a big difference in terms of improving SC performance. Hence, the averages metrics for BEST and WORST are relatively close. This fact is represented in Table 7 by the higher number of scenarios where the results obtained by the different strategies showed overlapping CIs. More specifically, we found overlapping CIs in $13.33 \%(B w S l)$ and $57.78 \%(\operatorname{Inv} A v)$ of the scenarios with $\psi_{L}$.

In order to quantify the impact of the adopted IS strategy on SC performance, we compare the performance obtained by the two extreme IS implementation strategies BEST and WORST, computing $\triangle B w S l_{W O R S T \rightarrow B E S T}(\%)$ and $\triangle I n v A v_{W O R S T \rightarrow B E S T}(\%)$ for all the SCs and partial IS structures. Table 8 shows the average results obtained from all the replications. Additionally, average values are shown for each SC (averaged for the three partial IS structures) as well as for each partial IS structure (averaged for all the SCs). 95\% CIs are computed for each partial IS structure.

Table 8. Relative SC performance improvement between WORST and BEST.

\begin{tabular}{|c|c|c|c|c|c|c|c|c|c|c|c|c|c|c|c|c|c|}
\hline & & & & & & & & & & & & & $\psi_{H}$ & & & & \\
\hline & $\Delta B v$ & ${ } S l_{W O R}$ & $T \rightarrow B E S T$ & $\%)$ & $\Delta I n v$ & $A v_{W O R}$ & $S T \rightarrow B E S$ & \%) & & $\Delta B v$ & $v S l_{W O R}$ & $T \rightarrow B E S T$ & $\%)$ & $\Delta \operatorname{In}$ & $A v_{W O R}$ & $T \rightarrow B E S T$ & $\%)$ \\
\hline & IRIS & $2 R I S$ & $3 R I S$ & Ave. & IRIS & $2 R I S$ & $3 R I S$ & Ave. & & $I R I S$ & $2 R I S$ & $3 R I S$ & Ave. & IRIS & $2 R I S$ & $3 R I S$ & Ave. \\
\hline $\mathrm{SC} 1$ & 5.67 & 7.67 & 8.18 & 7.17 & 4.06 & 3.15 & 2.18 & 3.13 & SC16 & 20.01 & 23.66 & 25.98 & 23.22 & 6.74 & 7.90 & 8.27 & 7.64 \\
\hline $\mathrm{SC} 2$ & 5.91 & 5.04 & 9.37 & 6.77 & 4.69 & 1.85 & 3.15 & 9.90 & SC17 & 28.03 & 36.73 & 36.78 & 33.84 & 8.24 & 9.56 & 9.53 & 9.11 \\
\hline SC3 & 8.72 & 15.73 & 12.78 & 12.41 & 3.01 & 4.93 & 1.96 & 3.30 & SC18 & 15.51 & 31.24 & 27.45 & 24.73 & 5.58 & 11.47 & 9.13 & 8.73 \\
\hline $\mathrm{SC} 4$ & 2.97 & 2.01 & 0.83 & 1.94 & 3.61 & 1.74 & 1.79 & 2.38 & SC19 & 19.26 & 29.68 & 33.84 & 27.59 & 6.37 & 10.92 & 10.98 & 9.43 \\
\hline SC5 & 7.29 & 10.49 & 15.83 & 11.21 & 4.06 & 2.90 & 3.78 & 3.58 & $\mathrm{SC} 20$ & 17.23 & 31.54 & 27.67 & 25.48 & 5.06 & 7.66 & 7.59 & 6.77 \\
\hline SC6 & 12.15 & 17.21 & 19.26 & 16.21 & 4.24 & 5.87 & 5.91 & 5.34 & $\mathrm{SC} 21$ & 18.50 & 32.12 & 28.16 & 26.26 & 5.29 & 8.29 & 6.39 & 6.66 \\
\hline SC7 & 8.42 & 12.44 & 12.63 & 11.16 & 3.48 & 2.70 & 3.31 & 3.17 & $\mathrm{SC} 22$ & 21.11 & 30.67 & 27.48 & 26.42 & 5.19 & 9.32 & 4.54 & 6.35 \\
\hline SC8 & 12.91 & 14.73 & 14.87 & 14.17 & 6.23 & 6.09 & 3.16 & 5.16 & $\mathrm{SC} 23$ & 26.02 & 35.56 & 37.02 & 32.87 & 8.85 & 9.95 & 10.94 & 9.91 \\
\hline SC9 & 8.57 & 15.59 & 12.44 & 12.20 & 2.17 & 5.35 & 2.66 & 3.39 & $\mathrm{SC} 24$ & 29.75 & 34.82 & 38.65 & 34.41 & 10.52 & 9.80 & 9.50 & 9.94 \\
\hline SC10 & 10.64 & 15.32 & 17.25 & 14.40 & 2.49 & 3.86 & 3.94 & 3.43 & $\mathrm{SC} 25$ & 18.17 & 28.23 & 25.40 & 23.93 & 5.29 & 6.79 & 6.50 & 6.19 \\
\hline SC11 & 3.30 & 2.97 & 5.47 & 3.91 & 2.86 & 2.22 & 1.25 & 2.11 & $\mathrm{SC} 26$ & 20.19 & 24.87 & 31.04 & 25.37 & 6.39 & 8.71 & 8.44 & 7.85 \\
\hline $\mathrm{SC} 12$ & 5.17 & 12.35 & 9.93 & 9.15 & 1.51 & 0.00 & 4.68 & 2.06 & $\mathrm{SC} 27$ & 17.77 & 24.50 & 27.00 & 23.09 & 6.54 & 9.02 & 7.88 & 7.81 \\
\hline $\mathrm{SC} 13$ & 5.43 & 7.60 & 8.16 & 7.06 & 3.78 & 1.68 & 2.30 & 2.59 & SC28 & 20.78 & 28.50 & 29.09 & 26.12 & 6.75 & 7.05 & 6.35 & 6.71 \\
\hline SC14 & 10.12 & 18.21 & 13.46 & 13.93 & 4.17 & 5.94 & 4.23 & 4.78 & SC29 & 24.08 & 30.39 & 31.89 & 28.79 & 8.78 & 8.27 & 7.57 & 8.20 \\
\hline SC15 & 3.46 & 6.98 & 3.68 & 4.70 & 3.22 & 0.29 & 2.22 & 1.91 & SC30 & 19.82 & 27.88 & 33.43 & 27.04 & 6.12 & 9.11 & 8.94 & 8.05 \\
\hline Ave. & 7.38 & 10.96 & 10.94 & 9.76 & 3.57 & 3.24 & 3.10 & 3.75 & Ave. & 21.08 & 30.03 & 30.73 & 27.28 & 6.78 & 8.92 & 8.17 & 7.96 \\
\hline \multirow{2}{*}{$95 \% \mathrm{CI}$} & 8.99 & 13.63 & 13.53 & 11.95 & 4.15 & 4.26 & 3.73 & 4.77 & \multirow{2}{*}{$95 \%$ CI } & 23.16 & 32.01 & 32.92 & 29.14 & 7.60 & 9.59 & 9.07 & 8.60 \\
\hline & 5.78 & 8.28 & 8.35 & 7.57 & 3.00 & 2.21 & 2.47 & 2.73 & & 19.01 & 28.04 & 28.54 & 25.42 & 5.96 & 8.25 & 7.27 & 7.32 \\
\hline
\end{tabular}


Dominguez, R., Cannella, S., Póvoa, A.P., Framinan, J.M. 2018. OVAP: A strategy to implement partial information sharing among supply chain retailers. Transportation Research Part E: Logistics and Transportation Review, 110, 122-136. DOI: https://doi.org/10.1016/j.tre.2017.12.016

For the SCs with $\psi_{L}$, results show an overall increase in $B w S l$ of $9.76 \%$, and an overall increase of $\operatorname{InvAv} 3.75 \%$, which are rather low figures that confirm the results in Table 7 for InvAv. However, performance differences are more relevant for the set of SCs in $\psi_{H}$, showing an overall increase in $B w S l$ of $27.28 \%$, and in $I n v A v$ of $7.96 \%$. Finally, for each partial IS structure, 95\% CIs suggest that differences between WORST and BEST are significantly higher for SCs in $\psi_{H}$ than for SCs in $\psi_{L}$. On the basis on these observations, we formalise the following finding:

(1) The IS implementation strategy adopted in a SC with heterogeneous retailers has a significant impact in terms of overall bullwhip effect and inventories.

\subsection{Testing the performance of OVAP}

In this section we test the performance of the proposed IS strategy (OVAP) by comparing its performance with that of BEST and WORST. We first benchmark OVAP vs BEST. Table 9 shows numeric results $\left(\Delta\right.$ metric $\left._{O V A P \rightarrow B E S T}(\%)\right)$ for all 30 SCs.

Table 9. Relative SC performance differences between OVAP and BEST.

\begin{tabular}{|c|c|c|c|c|c|c|c|c|c|c|c|c|c|}
\hline \multicolumn{7}{|c|}{$\psi_{L}$} & \multicolumn{7}{|c|}{$\psi_{H}$} \\
\hline & \multicolumn{3}{|c|}{$\Delta B w S l_{O V A P \rightarrow B E S T}(\%)$} & \multicolumn{3}{|c|}{$\triangle I n v A v_{O V A P \rightarrow B E S T}(\%)$} & & \multicolumn{3}{|c|}{$\Delta B w S l_{O V A P \rightarrow B E S T}(\%)$} & \multicolumn{3}{|c|}{$\triangle I n v A v_{O V A P \rightarrow B E S T}(\%)$} \\
\hline & IRIS & $2 R I S$ & $3 R I S$ & IRIS & $2 R I S$ & $3 R I S$ & & IRIS & $2 R I S$ & $3 R I S$ & $1 R I S$ & $2 R I S$ & $3 R I S$ \\
\hline $\mathrm{SC} 1$ & 0.84 & 0.55 & 1.01 & 0.46 & 0.53 & 0.61 & SC16 & 0.00 & 1.99 & 0.00 & 0.00 & 1.27 & 0.73 \\
\hline $\mathrm{SC} 2$ & 5.34 & 0.00 & 0.00 & 4.25 & 1.85 & 0.00 & SC17 & 0.00 & 0.00 & 1.75 & 0.00 & 0.00 & 2.57 \\
\hline $\mathrm{SC} 3$ & 0.00 & 0.00 & 0.00 & 0.00 & 0.00 & 0.00 & $\mathrm{SC} 18$ & 0.00 & 0.00 & 0.00 & 0.00 & 0.00 & 0.00 \\
\hline $\mathrm{SC} 4$ & 0.83 & 2.20 & 1.01 & 0.64 & 0.68 & 0.64 & SC19 & 0.00 & 0.00 & 0.00 & 0.00 & 0.13 & 0.00 \\
\hline SC5 & 0.00 & 0.68 & 0.00 & 0.00 & 0.22 & 0.00 & $\mathrm{SC} 20$ & 0.00 & 0.00 & 0.00 & 0.00 & 0.00 & 0.00 \\
\hline SC6 & 3.46 & 0.00 & 0.00 & 2.77 & 0.00 & 0.00 & $\mathrm{SC} 21$ & 0.00 & 0.00 & 0.00 & 0.00 & 0.00 & 0.00 \\
\hline SC7 & 0.00 & 0.00 & 1.89 & 0.00 & 0.00 & 0.00 & $\mathrm{SC} 22$ & 0.00 & 0.00 & 0.00 & 0.00 & 0.00 & 1.19 \\
\hline SC8 & 0.00 & 2.50 & 0.00 & 0.00 & 4.14 & 0.00 & $\mathrm{SC} 23$ & 0.00 & 0.00 & 0.00 & 0.00 & 0.00 & 0.00 \\
\hline SC9 & 5.67 & 0.00 & 0.00 & 0.40 & 0.00 & 0.00 & $\mathrm{SC} 24$ & 0.00 & 3.84 & 0.00 & 0.00 & 0.00 & 0.00 \\
\hline SC10 & 0.00 & 0.00 & 0.00 & 0.66 & 0.00 & 0.00 & $\mathrm{SC} 25$ & 0.00 & 0.00 & 0.00 & 0.00 & 0.00 & 2.13 \\
\hline SC11 & 1.33 & 2.66 & 3.18 & 1.14 & 0.21 & 0.50 & $\mathrm{SC} 26$ & 0.00 & 0.00 & 0.00 & 0.00 & 0.00 & 0.00 \\
\hline $\mathrm{SC} 12$ & 0.00 & 0.00 & 0.00 & 1.51 & 1.77 & 4.34 & SC27 & 0.00 & 0.00 & 0.00 & 0.00 & 0.00 & 0.00 \\
\hline $\mathrm{SC} 13$ & 3.04 & 0.00 & 0.00 & 3.78 & 0.55 & 0.38 & $\mathrm{SC} 28$ & 0.00 & 0.00 & 0.00 & 0.00 & 0.00 & 0.00 \\
\hline SC14 & 1.25 & 0.00 & 0.00 & 0.20 & 0.00 & 0.00 & $\mathrm{SC} 29$ & 0.00 & 0.00 & 0.00 & 0.00 & 0.00 & 1.12 \\
\hline SC15 & 0.00 & 1.35 & 1.47 & 0.00 & 0.00 & 2.36 & SC30 & 0.00 & 0.00 & 0.00 & 0.00 & 0.00 & 0.00 \\
\hline
\end{tabular}


Dominguez, R., Cannella, S., Póvoa, A.P., Framinan, J.M. 2018. OVAP: A strategy to implement partial information sharing among supply chain retailers. Transportation Research Part E: Logistics and Transportation Review, 110, 122-136. DOI: https://doi.org/10.1016/j.tre.2017.12.016

For SCs in $\psi_{L}$, OVAP does not equal BEST, as we observe perfect matches in $57.78 \%$ and $46.67 \%$ of the scenarios for $B w S l$ and $I n v A v$, respectively. In these scenarios, the observed differences oscillate between $[0.55 \%-5.67 \%]$ for $B w S l$ and between $[0.2 \%$ $4.34 \%$ ] for InvAv. On SCs in $\psi_{H}$, OVAP is similar to BEST in $93.33 \%$ and $84.44 \%$ of the scenarios for $B w S l$ and InvAv, respectively. For the instances where OVAP does not match BEST perfectly, the observed differences oscillate between [1.75\% - 3.84\%] for $B w S l$ and between [0.13\% - 2.57\%] for InvAv. Thus, we can conclude that OVAP is able to obtain results that are very close to those obtained by BEST, particularly for SCs in $\psi_{H}$. As a consequence, the results obtained for $\Delta B w S l_{W O R S T \rightarrow O V A P}(\%)$ and $\triangle I n v A v_{W O R S T \rightarrow O V A P}(\%)$ (Table 10$)$ are very similar to those obtained for $\triangle B W S l_{W O R S T \rightarrow B E S T}(\%)$ and $\triangle I n v A v_{W O R S T \rightarrow B E S T}(\%)($ Table 8$)$.

Table 10. Relative SC performance differences between OVAP and WORST.

\begin{tabular}{|c|c|c|c|c|c|c|c|c|c|c|c|c|c|c|c|c|c|}
\hline \multicolumn{9}{|c|}{$\psi_{L}$} & \multirow{2}{*}{\multicolumn{9}{|c|}{$\begin{array}{r}\psi_{H} \\
\Delta B w S l_{W O R S T \rightarrow O V A P}(\%)\end{array}$}} \\
\hline & \multicolumn{4}{|c|}{$\Delta B W S l_{\text {WORST } \rightarrow \text { OVAP }}(\%)$} & \multicolumn{4}{|c|}{$\triangle I n v A v_{W O R S T \rightarrow O V A P}(\%)$} & & & & & & & & & \\
\hline & IRIS & $2 R I S$ & $3 R I S$ & Ave. & IRIS & $2 R I S$ & $3 R I S$ & Ave. & & IRIS & $2 R I S$ & $3 R I S$ & Ave. & IRIS & $2 R I S$ & $3 R I S$ & Ave. \\
\hline Ave. & 5.98 & 10.67 & 10.65 & 9.10 & 2.50 & 2.84 & 2.60 & 2.65 & Ave. & 21.08 & 29.75 & 30.65 & 27.16 & 6.78 & 8.83 & 7.68 & 7.77 \\
\hline \multirow{2}{*}{$95 \% \mathrm{CI}$} & 7.85 & 13.39 & 13.38 & 11.35 & 3.39 & 3.83 & 3.42 & 3.32 & \multirow{2}{*}{$95 \% \mathrm{CI}$} & 23.16 & 31.75 & 32.79 & 28.96 & 7.60 & 9.54 & 8.75 & 8.45 \\
\hline & 4.11 & 7.95 & 7.92 & 6.86 & 1.61 & 1.85 & 1.78 & 1.98 & & 19.00 & 27.75 & 28.51 & 25.36 & 5.96 & 8.12 & 6.61 & 7.09 \\
\hline
\end{tabular}

These findings can be summarized as follows:

(2) The OVAP strategy to involve heterogeneous retailers into a partial IS structure (i.e., prioritizing those retailers with larger order's variance) performs, according to the levels of retailer heterogeneity,

a. $\left(\psi_{H}\right)$ similar (or very close) to BEST in $93.33 \%$ (BwSl) and $84.44 \%$ (InvAv) of the analysed scenarios.

b. $\left(\psi_{L}\right)$ similar (or very close) to BEST in $57.78 \%(\mathrm{BwSl})$ and $46.67 \%$ (InvAv) of the analysed scenarios.

(3) The OVAP strategy may obtain bullwhip and inventory reductions of

a. $\quad\left(\psi_{H}\right) \sim 27.2 \%$ and $\sim 7.8 \%$, respectively, with respect to the values obtained by WORST.

b. $\quad\left(\psi_{L}\right) \sim 9.1 \%$ and $\sim 2.7 \%$, respectively, with respect to the values obtained by WORST. 
Dominguez, R., Cannella, S., Póvoa, A.P., Framinan, J.M. 2018. OVAP: A strategy to implement partial information sharing among supply chain retailers. Transportation Research Part E: Logistics and Transportation Review, 110, 122-136. DOI: https://doi.org/10.1016/j.tre.2017.12.016

In order to get further insights on the adoption of the OVAP strategy, we measure its efficiency by comparing the performance improvement obtained by a partial IS structure (\#RIS) with that of a FIS, as per Equation (11). The behaviour of OVAP can be seen by plotting the function $f=\left(\# R I S, \Delta\right.$ metric $\left._{\# R I S / F I S}(\%)\right)$. In Figure 3 we plot $f$ for OVAP and WORST, averaging the results obtained for the 15 SCs of each set $\left(\psi_{L}\right.$ and $\left.\psi_{H}\right)$ and showing the $95 \%$ CIs.

$$
\Delta \text { metric }_{\# R I S / F I S}(\%)=\frac{\left(\text { metric }_{N I S}-\text { metric }_{\# R I S}\right)}{\left(\text { metric }_{N I S}-\text { metric }_{F I S}\right)} * 100
$$

of

Figure 3. $\Delta B w S l_{\# R I S / F I S}(\%)$ and $\Delta I n v A v_{\# R I S / F I S}(\%)$ for OVAP and WORST.

For SCs with $\psi_{H}$, OVAP shows an increasing concave function of the degree of retailer collaboration, while WORST shows an increasing convex function. Hence, since both curves share common start and end points, OVAP obtains most of the benefits provided by FIS with a low degree of retailer collaboration, while WORST performs clearly worse than FIS for any degree of retailer collaboration. In fact, a $1 R I S$ structure determined according to OVAP is able to achieve an average $44 \%(57.1 \%)$ of the total $B w S l$ (InvAv) reduction provided by a FIS, while a similar structure selected according to WORST is 
Dominguez, R., Cannella, S., Póvoa, A.P., Framinan, J.M. 2018. OVAP: A strategy to implement partial information sharing among supply chain retailers. Transportation Research Part E: Logistics and Transportation Review, 110, 122-136. DOI: https://doi.org/10.1016/j.tre.2017.12.016

only able to achieve an average $6.9 \%(16 \%)$ of the total $B w S l(I n v A v)$ reduction provided by a FIS. Similarly, a $3 R I S$ structure according to OVAP is able to achieve most of the benefits provided by a FIS (around $86 \%$ for both $B w S l$ and InvAv), while a similar structure according to WORST does not provide more than $42 \%$ of the benefits of a FIS.

For SCs with $\psi_{L}$, OVAP shows an increasing quasi-linear function for $B w S l$, which is reasonable, since retailers are quite similar. However, WORST still performs significantly worse than OVAP, showing an increasing convex function. InvAv shows overlapping results, as foreseeable from the results shown in Table 7. As a summary, we can conclude the following:

(4) The partial IS structure defined by OVAP in a SC with highly heterogeneous retailers performs only marginally worse than the FIS in terms of BwSl and InvAv, which may not be the case for other partial IS structures.

(5) For a SC where retailers are slightly heterogeneous, the partial IS structure defined by OVAP performs proportional to the FIS (according to the number of retailers involved) in terms of BwSl, which may not be the case for other partial IS structures.

\section{INDUSTRIAL RECOMMENDATIONS AND CONCLUDING REMARKS}

\subsection{Industrial recommendations}

The results in the previous section show that the strategy selected for retailers' adoption of IS is key to improve SC performance. This strategy is particularly relevant when retailers are highly heterogeneous (i.e., they have different operational configurations and/or customer demand). Conversely, a bad strategy may undermine investments in technology and efforts to establish collaboration practices due to the poor results obtained. Therefore, the strategy to incorporate retailers in IS needs to be carefully designed.

A first step for this design is to assess the heterogeneity of the retailers in the SC. Prior to implementing IS, information about retailers' demand (and other operational features such as the forecasting period or lead times) are unknown to SC managers, as they only have information about retailers' orders. As such, a way to assess the heterogeneity of 
Dominguez, R., Cannella, S., Póvoa, A.P., Framinan, J.M. 2018. OVAP: A strategy to implement partial information sharing among supply chain retailers. Transportation Research Part E: Logistics and Transportation Review, 110, 122-136. DOI: https://doi.org/10.1016/j.tre.2017.12.016

retailers is to compute the coefficient of variation of retailers' order variance, as described in Section 3.3. This single measure provides a simple indicator to estimate the levels of retailer heterogeneity, since it does not require obtaining and analysing a high amount of information from retailers.

If retailers show a high levels of heterogeneity, managers may adopt the OVAP strategy, i.e. selecting the retailers with higher order variance to be first included in the IS strategy. This strategy has been shown to achieve the highest bullwhip and inventory reduction for most scenarios analysed (i.e., $~ 93 \%$ for bullwhip and $\sim 84 \%$ for inventory). In addition, a partial IS structure implemented using the OVAP strategy is able to achieve a sizeable part of the total benefits from full IS: i.e. including just one of the four retailers in IS captures around $50 \%$ of the total benefits of full IS both in terms of bullwhip effect and average inventory reduction; by including an additional retailer these benefits rise up to around $70 \%$. These results provide further insights for conducting a trade-off analysis for determining the target number of collaborative retailers. More specifically, by assuming a linear increase of costs with the number of retailers involved in IS, a cost/benefit analysis may show, counterintuitively, that, in some cases, a partial IS structure is more beneficial than a full IS structure.

In summary, for a partial IS structure with a given number of collaborating retailers, OVAP presents the following advantages: (1) it exhibits a good exploitation of IS capability, providing a strategy to incorporate new retailers in the IS scheme by selecting those with the highest performance improvement; (2) only one type of information is required to prioritize retailers, removing the need of balancing different types of information and thus simplifying the process of selecting partners for IS.

\subsection{Concluding remarks}

This work analyses issues related to the implementation of the information sharing practice on heterogeneous retailers (i.e., they may have different operational configurations and/or customer demand, thus producing different order patterns) when only a partial collaboration can be achieved (i.e., due to several barriers only some retailers are going to share information upstream). Since retailers are heterogeneous, the benefits achieved by information sharing may depend critically on the specific retailers 
Dominguez, R., Cannella, S., Póvoa, A.P., Framinan, J.M. 2018. OVAP: A strategy to implement partial information sharing among supply chain retailers. Transportation Research Part E: Logistics and Transportation Review, 110, 122-136. DOI: https://doi.org/10.1016/j.tre.2017.12.016

that are involved and thus, the strategy adopted to include retailers in the information sharing scheme may have a significant impact on supply chain performance. Therefore, it is important to determine the impact of the adopted strategy on supply chain performance in order to implement information sharing at retailers, and to devise a strategy to share information with the retailers who potentially provide the highest performance improvement, considering that upstream members often lack of visibility on retailers' internal processes and policies. To this aim, we propose to adopt a strategy based on retailers' order variance (OVAP) (i.e., retailers with higher order variance are potentially better partners for information sharing) and to quantify the benefits of adopting such strategy in terms of bullwhip and average inventory reductions.

To accomplish the research objectives, we build a four echelon supply chain model with four retailers using SCOPE (a Multi-Agent based simulation tool), to analyse different partial IS scenarios at retailers. We generate a test-bed of 30 different SCs where retailers are heterogeneous (i.e., they have different market demands, lead times and forecasting period). We adopt the coefficient of variation of retailers' order variance as a measure of the levels of retailer heterogeneity. Finally, we use two benchmarking strategies, i.e., BEST and WORST. The former takes use of the results obtained from the simulations to identify and select the retailers who provide the best performance for the whole SC; similarly, the latter selects the retailers who provide the worst performance for the whole supply chain.

Results show that the adopted strategy to implement information sharing at retailers has a significant impact on supply chain performance, particularly for highly heterogeneous retailers. The proposed strategy OVAP performs almost identically to BEST $(93.33 \%$ (Bullwhip Slope) and $84.44 \%$ (Systemic Inventory Level) of the analysed scenarios) for highly heterogeneous retailers, obtaining an average $(\sim 27.2 \%)$ bullwhip and $(\sim 7.8 \%)$ inventory improvement over WORST. Thus, adopting the OVAP strategy to involve retailers in information sharing ensures exploitation of information sharing capability with heterogeneous retailers without the need of prior access to retailers' private information.

The present study has some limitations that may open room for future research. First of all, the number of retailers was fixed. A higher number of retailers may reduce the levels of retailer heterogeneity under the boundary conditions. How is the number of retailers 
Dominguez, R., Cannella, S., Póvoa, A.P., Framinan, J.M. 2018. OVAP: A strategy to implement partial information sharing among supply chain retailers. Transportation Research Part E: Logistics and Transportation Review, 110, 122-136. DOI: https://doi.org/10.1016/j.tre.2017.12.016

related to the levels of retailer heterogeneity? In addition, due to the inherent complexity of the problem under analysis, the study has been limited to the implementation of information sharing at retailers. It would be of interest to extend this research to other echelons of the chain, e.g., is the strategy adopted to implement information sharing at heterogeneous wholesalers also relevant to supply chain performance? How important is wholesaler heterogeneity for information sharing? Is OVAP also efficient at upstream echelons of the chain? How does the downstream supply chain/information sharing structure impact on the implementation of information sharing in the upstream echelons? Finally, it would be interesting to perform an integrated study of the implementation of partial information sharing in the supply chain as a whole (i.e., considering all echelons and all nodes) with heterogeneous members, and study the interactions that may arise between the different echelons. Naturally, in this type of analysis the structure of the supply chain may also play an important role.

\section{ACKNOWLEDGEMENTS}

This research was supported by the Portuguese Foundation for Science and Technology (Grant SFRH/BPD/108491/2015), by the Italian Ministry of Education, University and Research (Rita Levi Montalcini fellow), and by the Spanish Ministry of Science and Innovation, under the project PROMISE with reference DPI201680750P.

\section{REFERENCES}

Ali, M.M., Boylan, J.E., Syntetos, A.A. 2012. Forecast errors and inventory performance under forecast information sharing. International Journal of Forecasting, 28(4), 830-841.

Ali, M.M., Babai, M.Z., Boylan, J.E., Syntetos, A.A. 2017. Supply chain forecasting when information is not shared. European Journal of Operational Research, 260 (3), 984-994.

Babai, M.Z., Boylan, J.E., Syntetos, A.A., Ali, M.M. 2016. Reduction of the value of information sharing as demand becomes strongly auto-correlated. International Journal of Production Economics, 181, 130135.

Bischak, D.P., Robb, D.J., Silver, E.A., Blackburn, J.D. 2014. Analysis and management of periodic review, Order-Up-To level inventory systems with order crossover. Production and Operations Management, 23 (5), 762-772. 
Dominguez, R., Cannella, S., Póvoa, A.P., Framinan, J.M. 2018. OVAP: A strategy to implement partial information sharing among supply chain retailers. Transportation Research Part E: Logistics and Transportation Review, 110, 122-136. DOI: https://doi.org/10.1016/j.tre.2017.12.016

Cannella, S., Barbosa-Povoa, A.P., Framinan J.M., Relvas S. 2013. Metrics for bullwhip effect analysis. Journal of the Operational Research Society, 64, 1-16.

Cannella, S., Framinan, J. M., Bruccoleri, M., Barbosa-Póvoa, A. P., Relvas, S. 2015. The effect of inventory record inaccuracy in information exchange supply chains. European Journal of Operational Research, 243(1), 120-129.

Cannella, S., Dominguez, R., Framinan, J.M. 2017. Inventory record inaccuracy - The impact of structural complexity and lead time variability. Omega, 68, 123-138.

Chaharsooghi, S. K., Heydari, J. 2010. LT variance or LT mean reduction in supply chain management: Which one has a higher impact on SC performance?. International Journal of Production Economics, 124 (2), 475-481.

Chatfield, D.C., Kim, J.G., Harrison, T.P., Hayya, J.C. 2004. The bullwhip effect - Impact of stochastic lead time, information quality, and information sharing: A simulation study. Production and Operations Management, 13 (4), 340-353.

Chatfield, D.C. 2013. Underestimating the bullwhip effect: A simulation study of the decomposability assumption. International Journal of Production Research, 51 (1), 230-244.

Chatfield, D.C., Pritchard, A.M. 2013. Returns and the bullwhip effect. Transportation Research Part E: Logistics and Transportation Review, 49 (1), 159-175.

Chatfield, D.C., Hayya, J.C., Cook, D.P. 2013. Stockout propagation and amplification in supply chain inventory systems. International Journal of Production Research, 51 (5), 1491-1507.

Chatfield, D.C. Pritchard, A.M. 2017. Incorporating Order Crossover Information into Service-Oriented Base Stock Policy Decisions (July 18, 2017). Available at SSRN: https://ssrn.com/abstract=3006781

Chen, F., Drezner, Z., Ryan, J.K., Simchi-Levi, D. 2000. Quantifying the bullwhip effect in a simple supply chain: The impact of forecasting, lead times, and information. Management Science, 46 (3), 436-443.

Costantino, F., Di Gravio, G., Shaban, A., Tronci, M. 2014. The impact of information sharing and inventory control coordination on supply chain performances. Computers and Industrial Engineering, $76,292-306$.

Costantino, F., Di Gravio, G., Shaban, A., Tronci, M. 2015a. SPC forecasting system to mitigate the bullwhip effect and inventory variance in supply chains. Expert Systems with Applications, 42 (3), 17731787.

Costantino, F., Di Gravio, G., Shaban, A., Tronci, M. 2015b. A real-time SPC inventory replenishment system to improve supply chain performances. Expert Systems with Applications, 42 (3), 1665-1683.

Costantino, F., Di Gravio, G., Shaban, A., Tronci, M. 2016. Smoothing inventory decision rules in seasonal supply chains. Expert Systems with Applications, 44, 304-319. 
Dominguez, R., Cannella, S., Póvoa, A.P., Framinan, J.M. 2018. OVAP: A strategy to implement partial information sharing among supply chain retailers. Transportation Research Part E: Logistics and Transportation Review, 110, 122-136. DOI: https://doi.org/10.1016/j.tre.2017.12.016

Dejonckheere, J., Disney, S. M., Lambrecht, M. R., Towill, D. R. 2004. The impact of information enrichment on the Bullwhip effect in supply chains: A control engineering perspective. European Journal of Operational Research, 153 (3), 727-750.

Disney, S.M., Maltz, A., Wang, X., Warburton, R.D.H. 2016. Inventory management for stochastic lead times with order crossovers, European Journal of Operational Research, 248, 473-486.

Dominguez, R., Framinan, J.M. 2013. A decisión management tool: modelling the order fulfilment process by multi-agent systems. International Journal of Management and Decision Making, 12 (3), 240-258.

Dominguez, R., Cannella, S., Framinan, J.M. 2014. On bullwhip-limiting strategies in divergent supply chain networks. Computers and Industrial Engineering, 73 (1), 85-95.

Dominguez, R., Cannella, S., Framinan, J.M. 2015a. The impact of the supply chain structure on bullwhip effect. Applied Mathematical Modelling, 39 (23-24), 7309-7325.

Dominguez, R., Cannella, S., Framinan, J.M. 2015b. On returns and network configuration in supply chain dynamics. Transportation Research Part E: Logistics and Transportation Review, 73, 152-167.

Dominguez, R., Cannella, S., Barbosa-Povoa, A.P., Framinan, J.M. 2017. Information sharing in supply chains with heterogeneous retailers. Omega. Article in Press. DOI: 10.1016/j.omega.2017.08.005

Ganesh, M., Raghunathan, S., Rajendran, C. 2014a. Distribution and equitable sharing of value from information sharing within serial supply chains. IEEE Transactions on Engineering Management, 61 (2), 6573365, 225-236.

Ganesh, M., Raghunathan, S., Rajendran, C. 2014b. The value of information sharing in a multi-product, multi-level supply chain: Impact of product substitution, demand correlation, and partial information sharing. Decision Support Systems, 58 (1), 79-94.

Gunasekaran, A., Subramanian, N., Papadopoulos, T. 2017. Information technology for competitive advantage within logistics and supply chains: A review. Transportation Research Part E: Logistics and Transportation Review, 99, 14-33.

Gunasekaran, A., Subramanian, N., Rahman, S. 2015. Green supply chain collaboration and incentives: Current trends and future directions. Transportation Research Part E: Logistics and Transportation Review, 74, 1-10

Gümüş, M. 2014. With or without forecast sharing: Competition and credibility under information asymmetry. Production and Operations Management, 23 (10), 1732-1747.

Hayya, J.C., Bagchi, U., Kim, J.G., Sun, D. 2008. On static stochastic order crossover. International Journal of Production Economics, 114 (1), 404-413.

Hayya, J.C., Bagchi, U., Ramasesh, R. 2011. Cost relationships in stochastic inventory systems: A simulation study of the (S, S-1, t=1) model. International Journal of Production Economics, 130 (2), 196-202. 
Dominguez, R., Cannella, S., Póvoa, A.P., Framinan, J.M. 2018. OVAP: A strategy to implement partial information sharing among supply chain retailers. Transportation Research Part E: Logistics and Transportation Review, 110, 122-136. DOI: https://doi.org/10.1016/j.tre.2017.12.016

Hoberg, K., Thonemann, U.W. 2014. Modeling and analyzing information delays in supply chains using transfer functions. International Journal of Production Economics, 156, 132-145.

Holmstrőm, J., Småros, J., Disney, S.M., Towill, D.R. 2016. Collaborative supply chain configurations: the implications for supplier performance in production and inventory control. In Developments in Logistics and Supply Chain Management (pp. 27-37). Palgrave Macmillan UK.

Hosoda, T., Disney, S.M. 2012. A delayed demand supply chain: Incentives for upstream players. Omega, $40,478-487$.

Huang, B., Iravani, S.M.R. 2005. Production control policies in supply chains with selective-information sharing. Operations Research, 53 (4), 662-674.

Huang, Y.-S., Li, M.-C., Ho, J.-W. 2016. Determination of the optimal degree of information sharing in a two-echelon supply chain. International Journal of Production Research, 54 (5), 1518-1534.

Huang, Y.-S., Hung, J.-S., Ho, J.-W. 2017. A study on information sharing for supply chains with multiple suppliers. Computers and Industrial Engineering, 104, 114-123.

Huang, Y., Wang, Z. 2017. Values of information sharing: A comparison of supplier-remanufacturing and manufacturer-remanufacturing scenarios. Transportation Research Part E: Logistics and Transportation Review, 106, 20-44.

Inderfurth, K., Sadrieh, A., Voigt, G. 2013. The impact of information sharing on supply chain performance under asymmetric information. Production and Operations Management, 22 (2), 410-425.

Jeong, I.-J., Jorge Leon, V. 2012. A serial supply chain of newsvendor problem with safety stocks under complete and partial information sharing. International Journal of Production Economics, 135 (1), 412419.

Kembro, J., Selviaridis, K., Näslund, D. 2014. Theoretical perspectives on information sharing in supply chains: a systematic literature review and conceptual framework. Supply Chain Management: An International Journal, 19, 609-625.

Kembro, J., Selviaridis, K. 2015. Exploring information sharing in the extended supply chain: an interdependence perspective. Supply Chain Management: An International Journal, 20 (4), pp. 455470.

Kim, J.G., Chatfield, D., Harrison, T.P., Hayya, J.C. 2006. Quantifying the bullwhip effect in a supply chain with stochastic lead time. European Journal of Operational Research, 173 (2), 617-636.

Kong, G., Rajagopalan, S., Zhang, H. 2013. Revenue sharing and information leakage in a supply chain. Management Science, 59 (3), 556-572.

Kwak, J.K., Gavirneni, S. 2015. Impact of information errors on supply chain performance. Journal of the Operational Research Society, 66 (2), pp. 288-298. 
Dominguez, R., Cannella, S., Póvoa, A.P., Framinan, J.M. 2018. OVAP: A strategy to implement partial information sharing among supply chain retailers. Transportation Research Part E: Logistics and Transportation Review, 110, 122-136. DOI: https://doi.org/10.1016/j.tre.2017.12.016

Langroodi, R.R.P., Amiri, M. 2016. A system dynamics modeling approach for a multi-level, multiproduct, multi-region supply chain under demand uncertainty. Expert Systems with Applications, 51, 231-244.

Lau, J.S.K., Huang, G.Q., Mak, K.L. 2004. Impact of information sharing on inventory replenishment in divergent supply chains. International Journal of Production Research, 42 (5), 919-941.

Lee, H.L., Padmanabhan, V., Whang, S. 1997. Information distortion in a Supply Chain: The Bullwhip effect. Management Science, 43 (4), 546-558.

Lee, H.L., Whang, S. 2000. Information sharing in a supply chain. International Journal of Technology Management, 20 (3), 373-387.

Li, G., Zhang, L., Guan, X., Zheng, J. 2016. Impact of decision sequence on reliability enhancement with supply disruption risks. Transportation Research Part E: Logistics and Transportation Review, 90, 25 38.

Li, Q., Disney, S.M., Gaalman, G. 2014. Avoiding the bullwhip effect using Damped Trend forecasting and the Order-Up-To replenishment policy. International Journal of Production Economics, 149, 3-16.

Li, Q., Disney, S. M. 2017. Revisiting rescheduling: MRP nervousness and the bullwhip effect. International Journal of Production Research, 55(7), 1992-2012.

Lin, H. J. 2016. Investing in lead-time variability reduction in a collaborative vendor-buyer supply chain model with stochastic lead time. Computers \& Operations Research, 72, 43-49.

Long, Q. 2015. Three-dimensional-flow model of agent-based computational experiment for complex supply network evolution. Expert Systems with Applications, 42 (5), 2525-2537.

Minar, N., Burkhart, R., Langton, C., Askenazi, M. 1996. The Swarm simulation system: A toolkit for building multi-agent simulations. Working Paper 96-06-042, Santa Fe Institute, Santa Fe.

Nachtmann, H., Waller, M.A., Rieske, D.W. 2010. The impact of point-of-sale data inaccuracy and inventory record data errors. Journal of Business Logistics, 31 (1), 149-158.

Niranjan, T.T., Wagner, S.M., Aggarwal, V. 2011. Measuring information distortion in real-world supply chains. International Journal of Production Research, 49 (11), pp. 3343-3362.

Ponte, B., Costas, J., Puche, J., De la Fuente, D., Pino, R. 2016. Holism versus reductionism in supply chain management: An economic analysis. Decision Support Systems, 86, 83-94.

Ponte, B., Sierra, E., de la Fuente, D., Lozano, J. 2017. Exploring the interaction of inventory policies across the supply chain: An agent-based approach. Computers \& Operations Research, 78, 335-348.

Rached, M., Bahroun, Z., Campagne, J.-P. 2015. Assessing the value of information sharing and its impact on the performance of the various partners in supply chains. Computers and Industrial Engineering, 88, 237-253. 
Dominguez, R., Cannella, S., Póvoa, A.P., Framinan, J.M. 2018. OVAP: A strategy to implement partial information sharing among supply chain retailers. Transportation Research Part E: Logistics and Transportation Review, 110, 122-136. DOI: https://doi.org/10.1016/j.tre.2017.12.016

Rached, M., Bahroun, Z., Campagne, J.-P. 2016. Decentralised decision-making with information sharing vs. centralised decision-making in supply chains. International Journal of Production Research, 54 (24), 7274-7295.

Ramanathan, U. 2014. Performance of supply chain collaboration - A simulation study. Expert Systems with Applications, 41 (1), 210-220.

Rekik, Y., Glock, C. H., Syntetos, A.A. 2017. Enriching demand forecasts with managerial information to improve inventory replenishment decisions: Exploiting judgment and fostering learning. European Journal of Operational Research, 261(1), 182-194.

Shan, J., Yang, S., Yang, S., Zhang, J. 2014. An empirical study of the bullwhip effect in China. Production and Operations Management, 23 (4), 537-551.

Shang, W., Ha, A.Y., Tong, S. 2016. Information sharing in a supply chain with a common retailer. Management Science, 62 (1), 245-263.

Shih, H.P., Lai, K.H., Cheng, T.E. 2015. Examining structural, perceptual, and attitudinal influences on the quality of information sharing in collaborative technology use. Information Systems Frontiers, 17 (2), 455-470.

Shnaiderman, M., Ouardighi, F.E. 2014. The impact of partial information sharing in a two-echelon supply chain. Operations Research Letters, 42 (3), 234-237.

Spekman, R., Davis, E.W. 2016. The extended enterprise: a decade later. International Journal of Physical Distribution \& Logistics Management, 46 (1), 43-61.

Sterman, J. 1989. Modeling managerial behavior: misperceptions of feedback in a dynamic decision making experiment. Management Science, 35 (3), 321-339.

Syntetos, A.A., Kholidasari, I., Naim, M. M. 2016a. The effects of integrating management judgement into OUT levels: In or out of context?. European Journal of Operational Research, 249 (3), 853-863.

Syntetos, A., Babai, Z., Boylan, J.E., Kolassa, S., Nikolopoulos, K. 2016b. Supply Chain Forecasting: Theory, Practice, their Gap and the Future, European Journal of Operational Research, 252 (1), 1-26.

Trapero, J.R., Kourentzes, N., Fildes, R. 2012. Impact of information exchange on supplier forecasting performance. Omega, 40 (6), 738-747.

Wan, X., Evers, P.T. 2011. Supply chain networks with multiple retailers: a test of the emerging theory on inventories, stockouts, and bullwhips. Journal of Business Logistics, 32 (1), 27-39.

Wang, X., Disney, S.M. 2016. The bullwhip effect: Progress, trends and directions, European Journal of Operational Research, 250 (3), 691-701.

Xu, K., Dong, Y., Xia, Y. 2015. 'Too little' or 'Too late': The timing of supply chain demand collaboration. European Journal of Operational Research, 241 (2), 370-380.

Yu, M.-M., Ting, S.-C., Chen, M.-C. 2010. Evaluating the cross-efficiency of information sharing in supply chains. Expert Systems with Applications, 37 (4), 2891-2897. 
Dominguez, R., Cannella, S., Póvoa, A.P., Framinan, J.M. 2018. OVAP: A strategy to implement partial information sharing among supply chain retailers. Transportation Research Part E: Logistics and Transportation Review, 110, 122-136. DOI: https://doi.org/10.1016/j.tre.2017.12.016

Zhang, H., Lee, C. Y., Li, T. 2016. The value of specific cargo information for substitutable modes of inland transport. Transportation Research Part E: Logistics and Transportation Review, 85, 23-39.

Zhou, X., Ma, F., Wang, X. 2009. An incentive model of partial information sharing in supply chain. 2009 IEEE/INFORMS International Conference on Service Operations, Logistics and Informatics, SOLI 2009, 5203904, 58-61.

Zhou, M., Dan, B., Ma, S., Zhang, X. 2017a. Supply chain coordination with information sharing: The informational advantage of GPOs. European Journal of Operational Research, 256 (3), 785-802.

Zhou, L., Naim, M. M., \& Disney, S. M. 2017b. The impact of product returns and remanufacturing uncertainties on the dynamic performance of a multi-echelon closed-loop supply chain. International Journal of Production Economics, 183, 487-502 